\title{
ANALISIS NILAI TAMBAH PRODUK OLAHAN MANGGA (Studi Kasus Pada Produk Mango Fruit Strips Frutivez)
}

\section{VALUE ADDED ANAL YSIS OF PROCESSED MANGO PRODUCT (Case Studies of Fruit Stirps Mango Product in Frutivez)}

\author{
Yuniar Dianti Fauziah*, Elly Rasmikayati ${ }^{1}$, Bobby Rachmat Saefudin ${ }^{2}$ \\ ${ }^{1}$ Fakultas Pertanian, Universitas Padjadjaran, J1. Bandung-Sumedang KM. 21, Jatinangor, 45363 \\ ${ }^{2}$ Fakultas Pertanian, Ma'soem University, Jl. Raya Cipacing No.22, Jatinangor 45363 \\ *E-mail: yuniar17002@mail.unpad.ac.id \\ (Diterima 02-02-2021; Disetujui 03-06-2021)
}

\begin{abstract}
ABSTRAK
Buah mangga merupakan salah satu kelompok buah musiman yang memiliki potensi untuk diolah menjadi produk olahan. Proses pengolahan menjadi salah satu solusi saat harga jual buah yang rendah pada musim panen serta banyak hasil panen yang terbuang sia-sia karena terlalu lama disimpan. Bahan baku yang telah mengalami perubahan nilai tersebut dapat diperkirakan seberapa besar nilainya. Maka tujuan dari penelitian ini adalah mendeskripsikan latar belakang terbentuknya produk olahan mango fruit strips dari Frutivez serta menganalisis nilai tambah dari produk tersebut. Desain penelitian yang digunakan adalah menggunakan desain kuantitatif studi kasus dengan metode wawancara. Analisis data dilakukan dengan analisis nilai tambah metode hayami. Hasil penelitian menunjukkan bahwa dalam satu kali proses produksi nilai tambah yang diperoleh produk adalah sebesar Rp 5.000/kg dengan rasio 11\% dimana setiap Rp 100 nilai produk mango fruit strips mengandung nilai tambah sebesar $\mathrm{Rp} 11$.
\end{abstract}

Kata Kunci: Nilai tambah, produk olahan, buah mangga, inovasi, metode hayami

\section{ABSTRACT}

Mango fruit is one of the seasonal fruit groups that have the potential to be processed into processed products. The processing process is one of solution when the selling price of fruit is low during the harvest season and a lot of the harvest is wasted because it is stored too long. Raw materials that have run into a change in value can be estimated how much their value is. So the purpose of this study is to describe the background of the formation of the processed mango fruit strips from Frutivez and to analyze the added value of these products. The research design used is to use a quantitative design of case studies with the interview method. Data analysis was carried out by using the added value analysis of the Hayami method. The results showed that in one production process the added value obtained by the product was IDR 5,000/ $\mathrm{kg}$ with a ratio of $11 \%$, where every IDR 100 the value of the mango fruit strips product contained an added value of IDR 11 .

Keywords: Value added, processed product, mango fruit, innovation, hayami method

\section{PENDAHULUAN}

Buah mangga merupakan salah satu komoditas hortikultura terbesar kedua yang paling sering dikonsumsi di dunia dengan presentase 28\% (De La Fuente, 2016). Di Indonesia sendiri, buah mangga merupakan buah dengan jumlah volume produksi tertinggi kedua yaitu sebesar 2.808.936 ton tahun 2019 (BPS, 2019). Terdapat tiga daerah yang menjadi kontributor terbesar terhadap produksi nasional diantaranya Provinsi Jawa 
Timur, Jawa Tengah dan Jawa Barat. Namun mengingat sifat dari buah mangga yang termasuk kedalam kelompok buah musiman maka produksi dalam satu tahunnya selalu mengalami fluktuasi. Terjadinya lonjakan produksi yang sangat tinggi saat memasuki puncak panen raya pada bulan Oktober hingga November menyebabkan harga buah dipasaran menjadi sangat rendah. Harga jual mangga di tingkat petani saat musim dan diluar musim mempunyai perbedaan yang cukup besar contohnya pada saat diluar musim harga jual dapat berkisar antara Rp 10.000 sampai Rp 30.000 per kilogram, sedangkan saat memasuki musim panen harga dapat turun hingga Rp 7.000 sampai Rp 20.000 per kilogram (Rasmikayati dkk., 2017).

Selain dari turunnya harga jual pada musim panen, banyaknya buah mangga yang terbuang sia-sia karena tidak terjual dan sulitnya konsumen mendapatkan buah diluar musim menjadi salah satu tantangan tersendiri untuk para produsen (Rasmikayati dkk, 2020). Maka salah satu alternatif yang dapat dilakukan untuk membantu meningkatkan pendapatan dan mengoptimalisasikan hasil panen adalah dengan melakukan proses pengolahan. Pengolahan makanan atau minuman memroses buah menjadi bentuk bubuk, pasta dan produk olahan lainnya melalui proses pengeringan yang tinggi. Menurut Anitasari dkk. (2014) bahan baku yang berasal dari mangga kualitas off grade namun masih baik dapat menghasilkan pendapatan agroindustri mangga dalam sekali proses produksi. Hasil tersebut menunjukkan bahwa terdapat nilai positif yang dapat diperoleh per satuan bahan baku untuk menghasilkan produk olahan mangga. Dengan adanya proses pengolahan tersebut dapat mendorong harga jual yang turut meningkat serta menjadikan umur simpan produk lebih lama sehingga konsumen masih bisa mengonsumi buah mangga diluar musim panen.

Terjadinya proses pengolahan akan menimbulkan pertambahan nilai pada komoditas buah mangga. Perubahan nilai bahan baku yang telah mengalami perlakuan seperti proses pengolahan, pengangkutan maupun penyimpanan dalam suatu proses produksi disebut dengan nilai tambah atau value added. Maka dari pengertian tersebut dapat diketahui bahwa bahan baku yang telah mengalami perubahan nilai dapat diperkirakan seberapa besar nilainya. Nilai tambah yang semakin besar nantinya dapat berperan untuk meningkatkan pertumbuhan ekonomi. 
Menurut Siafunda (2019), perusahaan pengolahan mangga saat ini sangat menguntungkan karena memiliki pasar yang besar, khususnya di Zambia terutama dalam periode produksi mangga yang sedang melambat atau saat diluar musim panen. Pada hasil penelitiannya terdapat tiga pemain pasar dengan profitabilitas yang menunjukkan produsen memiliki margin laba bersih $18,34 \%$, pedagang $19,45 \%$ dan perusahaan pengolahan $34,1 \%$. Hal tersebut membuktikan bahwa pengolahan akan membantu mengurangi pemborosan dan pada saat yang sama dapat menghasilkan keuntungan dari model bisnis yang baru.

Terdapat beberapa contoh produk olahan yang dapat dibuat dari buah mangga seperti jus atau minuman sari buah, puree, yogurt, selai, es krim, dodol, manisan, keripik, rujak, asinan dan lainnya (Rasmikayati et al., 2020). Produk-produk olahan tersebut tentunya memiliki nilai tambah yang berbeda-beda tergantung pada biaya yang dikeluarkan oleh produsen. Salah satu keuntungan yang diperoleh dengan adanya proses pengolahan buah mangga menjadi puree di Kabupaten Cirebon selama satu bulan dengan 15 kali proses produksi adalah sebesar Rp 37.862.521 dengan rasio kelayakan sebesar 1,22. Nilai tambah yang diperoleh per $1 \mathrm{~kg}$ manga adalah sebesar Rp3.122 untuk mangga harumanis sedangkan mangga gedong sebesar Rp3.622 (Royanti, 2018).

Menurut hasil penelitian Zainudhin (2016), perhitungan nilai tambah terbesar pada produk olahan buah mangga diraih oleh produk dodol mangga yaitu senilai $\mathrm{Rp}$ 63.654,86/kg dengan rasio nilai tambah 58,97\% kemudian disusul nilai tambah terbesar lainnya pada produk keripik mangga yaitu sebesar Rp 26.440,31 dengan rasio nilai tambah $70,05 \%$. Sedangkan nilai tambah terkecil dimiliki produk olahan yang membuat sari buah mangga yakni Rp 8.254,43 dengan rasio nilai tambah $34,68 \%$, hal tersebut terjadi karena harga jual per kemasan hanya $\mathrm{Rp} 1.000$. Sehingga dengan adanya perhitungan nilai tambah tersebut menjadi penting untuk acuan produsen bahwa produk olahan yang dibuat memiliki kriteria yang positif untuk dipasarkan.

Seiring berkembangnya zaman dan perubahan gaya hidup, produk olahan mangga telah dikembangkan menjadi sebuah produk inovasi yang tidak hanya berfungsi sebagai camilan namun dapat dinikmati sebagai makanan camilan yang sehat. Salah satu contohnya adalah 
produk fruit strips mango dari Frutivez yang dikembangkan oleh salah satu lulusan mahasiswa pada Fakultas Teknologi Industri Pertanian di Universitas Padjadjaran. Fruit strips mango merupakan olahan buah yang dipotong tipis lalu dikeringkan menggunakan metode dehidrasi sehingga nutrisi pada buah tidak akan rusak dan tidak terbuang dengan jumlah yang banyak. Hadirnya produk inovasi baru dari Frutivez memiliki tantangan dalam proses penerimaan dan pengenalan produk kepada masyarakat.

Menurut Griffin (1997), dengan adanya pengembangan produk olahan baru harus memperhatikan beberapa hal diantaranya adalah meningkatkan nilai tambah produk dalam tingkat persaingan tertentu. Daya saing dari produk Frutivez dapat diukur dengan pendekatan nilai tambah. Menurut Hayami (1987), pendekatan nilai tambah dipengaruhi oleh 2 faktor. Yang pertama adalah faktor teknis seperti kapasitas produksi, penerapan teknologi, kualitas produk, kualitas bahan baku dan input tamabahan dan yang kedua adalah faktor pasar seperti harga jual output, upah tenaga kerja dan harga bahan baku. Perhitungan nilai tambah tersebut menjadi penting untuk acuan bahwa produk olahan yang dibuat memiliki keuntungan dan kriteria yang positif untuk dipasarkan. Sehingga penelitian ini bertujuan untuk menganalisis usaha serta nilai tambah produk olahan buah mangga yaitu mango stripes dari Frutivez.

\section{METODE PENELITIAN}

Penelitian ini dilakukan di Kecamatan Jatinangor, Jawa Barat yaitu tempat produksi sekaligus kantor dari Frutivez pada bulan Januari 2021. Rancangan penelitian ini dilakukan dengan desain kuantitatif dan metode wawancara. Wawancara dilakukan bersama CEO (Chief Excecutive Officer) dan CMO (Chief Marketing Officer) dari Frutivez selaku informan dalam penelitian ini. Dalam proses wawancara dibantu dengan instrument penelitian berupa kuesioner.

Terdapat tiga variabel yang digunakan untuk memperhitungkan nilai tambah diantaranya: output, input dan harga; penerimaan dan keuntungan; serta balas jasa pemilik faktor produksi.

Analisis data yang digunakan untuk menghitung nilai tambah pada penelitian ini menggunakan analisis nilai tambah metode hayami. Menurut Hayami (1987), nilai tambah adalah selisih lebih harga antara komoditas yang mendapat 
perlakuan pada tahap tertentu dengan nilai yang digunakan selama proses berlangsung. Berikut adalah prosedur perhitungan nilai tambah metode hayami.

Tabel 1. Analisis Nilai Tambah Metode Hayami

\begin{tabular}{|c|c|c|c|}
\hline Variabel & No. & Sub Variabel & Keterangan \\
\hline \multirow{7}{*}{$\begin{array}{l}\text { Output, Input } \\
\text { dan Harga }\end{array}$} & 1. & Output (Kg) & (1) \\
\hline & 2. & Input Bahan Baku (Kg) & (2) \\
\hline & 3. & Tenaga kerja langsung (Jam/Hari) & (3) \\
\hline & 4. & Faktor konversi & $(4)=(1) /(2)$ \\
\hline & 5. & Koefisien tenaga kerja (Jam/Kg) & $(5)=(3) /(2)$ \\
\hline & 6. & Harga produk $(\mathrm{Rp} / \mathrm{Kg})$ & (6) \\
\hline & 7. & Upah tenaga kerja (Rp/Jam) & (7) \\
\hline \multirow{9}{*}{$\begin{array}{l}\text { Penerimaan } \\
\text { dan } \\
\text { Keuntungan }\end{array}$} & 8. & Harga input bahan baku $(\mathrm{Rp} / \mathrm{Kg})$ & (8) \\
\hline & 9. & Sumbangan input lain $(\mathrm{Rp} / \mathrm{Kg})$ & (9) \\
\hline & 10. & Nilai Output (Rp/Kg) & $(10)=(4) \times(6)$ \\
\hline & 11. & a. Nilai tambah $(\mathrm{Rp} / \mathrm{Kg})$ & $(11 \mathrm{a})=(10)-(8)-(9)$ \\
\hline & & b. Rasio nilai tambah (\%) & $(11 b)=(11 a) /(10) \times 100 \%$ \\
\hline & 12. & a. Pendapatan tenaga kerja (Rp/Jam) & $(12 a)=(5) x(7)$ \\
\hline & & b. Pangsa tenaga kerja $(\%)$ & $(12 b)=(12 a) /(11 a) \times 100 \%$ \\
\hline & 13. & a. Keuntungan $(\mathrm{Rp} / \mathrm{Kg})$ & $(13 a)=(11 a)-(12 a)$ \\
\hline & & b. Tingkat keuntungan $(\%)$ & $(13 b)=(13 a) /(10) \times 100 \%$ \\
\hline \multirow{4}{*}{$\begin{array}{c}\text { Balas Jasa } \\
\text { Pemilik Faktor } \\
\text { Produksi }\end{array}$} & 14. & Marjin $(\mathrm{Rp} / \mathrm{Kg})$ & $(14)=(10)-(8)$ \\
\hline & & a. Pendapatan tenaga kerja $(\%)$ & $(14 a)=(12 a) /(14) \times 100 \%$ \\
\hline & & b. Sumbangan input lain $(\%)$ & $(14 b)=(9) /(14) \times 100 \%$ \\
\hline & & c. Keuntungan perusahaan $(\%)$ & $(14 c)=(13 a) /(14) \times 100 \%$ \\
\hline
\end{tabular}

\section{HASIL DAN PEMBAHASAN}

\section{Latar Belakang dan Gambaran Umum}

\section{Frutivez}

Berawal dari fenomena buah mangga yang bersifat musiman dimana harga jual saat musim panen raya terjadi penurunan yang sangat drastis. Selain itu terdapat buah mangga yang tidak lulus grading terbuang sia-sia. Dari situlah muncul ide memanfaatkan buah mangga untuk dikembangkan menjadi produk inovasi camilan buah yang sehat berupa fruit strips. Munculnya fruit strips ini menjadikan produk inovasi pertama yang ada di Indonesia. Produknya sendiri terbuat dari $100 \%$ buah mangga asli tanpa menggunakan bahan tambahan seperti gula, pengawet maupun pewarna.

Dimulai dalam masa studinya tahun 2017, Kang Rijaldi selaku founder dan CEO dari Frutivez mulai mengembangkan fruit strips. Pada mulanya dengan nama Mango Day, dibawah naungan oorange unpad selaku inkubator bisnis di Universitas Padjadjaran sering aktif mengikuti beberapa acara untuk memperkenalkan produknya.

Pada tahun 2018, produk fruit strips sudah mulai diproduksi karena melihat bahwa pasarnya mulai terbuka untuk produk inovasi camilan sehat. Dengan 
adanya perubahan gaya hidup dimana masyarakat mulai sadar akan pentingnya kesehatan, fruit strips ini menjadi salah satu solusi agar masyarakat tetap dapat mengonsumsi buah secara praktis, mudah dan tentunya sehat.

Hingga pada tahun 2019 produk fruit strips hadir dengan nama baru yaitu Frutivez dan sudah mulai aktif dijual pada sekitar bulan februari dan berlanjut sampai sekarang. Produknya sudah tersedia di cafe pada wilayah Bandung dan supermarket pada wilayah Bekasi, Jakarta dan Tangerang Selatan. Selain itu penjualan produknya juga sudah tersedia pada online store seperti pada beberapa market place yaitu Blibli, Shopee dan Tokopedia untuk menjangkau konsumen lebih luas lagi.

\section{Proses Produksi Mango Fruit Strips}

Dalam proses produksinya, buah mangga yang digunakan dari Mango Fruit Strips ini diambil dari petani mangga gedong gincu Cirebon, Indramayu dan Sumedang. Dengan memanfaatkan buah mangga yang memiliki kualitas off grade para petani tersebut melakukan pengolahan menjadi puree mangga yang selanjutnya akan dilakukan proses berikutnya menggunakan teknologi dehidrasi oleh tim produksi dari Frutivez. Dengan menggunakan bahan baku berbentuk puree tersebut produk olahan tetap dapat diproses baik diluar musim maupun pada saat memasuki musim panen.

Untuk mendapatkan hasil yang maksimal, proses dehidrasi memakan waktu kurang lebih 20 jam dalam satu kali proses produksinya mulai dari tahap awal hingga tahap pengemasan produk. Penggunaan alat yang diimpor dan biaya listrik yang tentunya sangat tinggi menjadi salah satu tantangan untuk nantinya dapat menghasilkan produk yang berkualitas.

Proses produksi yang dilakukan tidak memiliki jadwal tertentu namun, melihat pada minimum ketersediaan stok yang sudah ditentukan dari perusahaan. Sehingga jika memang penjualan produk sedang tinggi maka proses produksi yang dilakukan akan bertambah. Sedangkan jika penjualan produk sedang melambat maka proses produksi tidak akan dilakukan terlebih dahulu. Dengan umur simpan bahan baku yang lebih lama karena berbahan puree maka tidak akan mempengaruhi proses produksi walaupun berada diluar musim panen buah mangga.

Tenaga kerja yang digunakan dalam proses produksi adalah sebanyak 3 orang dengan kapasitas 4.500 kemasan perbulannya. Dalam satu bulan total hari 
kerja yang digunakan adalah 20 hari dengan jam kerja selama 8 jam per hari.

\section{Produk Mango Fruit Strips}

Produk mango fruit strips merupakan inovasi pertama yang ada di Indonesia. Bentuk dari produk tersebut sesuai dengan namanya yaitu berupa potongan strip yang tipis sehingga mudah untuk dikonsumsi baik untuk anak-anak, dewasa maupun lansia (lanjut usia). Dalam satu kemasan produk setara manfaatnya masih setara dengan satu buah mangga gedong gincu sehingga aman untuk kesehatan karena tidak memakai bahan tambahan lainnya.

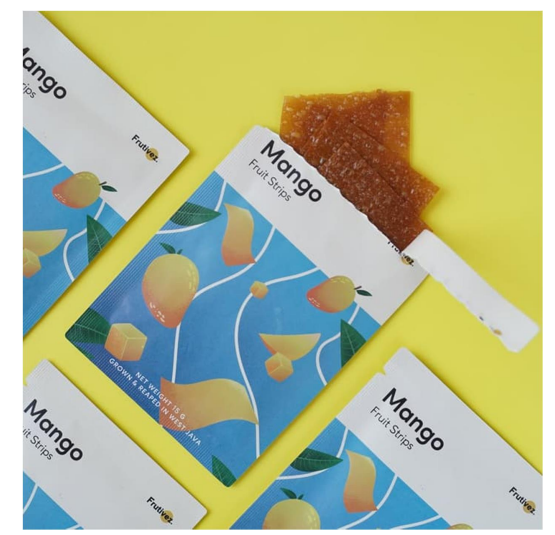

\section{Gambar 1. Bentuk Mango Fruit Strips}

Sumber: Instagram.com/frutivez

Dari segi penggunaan kemasan yang digunakan bahan maupun bentuknya sudah dirancang oleh perusahaan agar praktis, mudah dibawa dan mudah disimpan bagi konsumen. Produk Mango Fruit Strips ini memiliki umur simpan $>6$ bulan sehingga konsumen dapat mengonsumsi produk tanpa mengenal musim.

\section{Perhitungan Nilai Tambah Produk Mango Fruit Strips}

Perhitungan analisis nilai tambah merupakan selisih lebih antara harga produk dengan harga bahan baku dan sumbangan input lainnya. Jika nilai tambah suatu produk semakin tinggi maka timbul persaingan yang ketat di pasaran karena produk dinilai semakin menguntungkan (Suardani dkk., 2016). Analisis nilai tambah sangat penting untuk dilakukan sebagai perhitungan balas jasa yang diperoleh produsen atau pelaku usaha serta dapat mengukur kesempatan kerja yang tercipta (Herdiyandi dkk., 2006).

Sejauh ini penelitian analisis nilai tambah yang ada hanya mengacu pada produk olahan pada umumnya seperti jus atau puree, dodol dan keripik. Belum ada yang mengulas perhitungan analisis pada produk inovasi seperti fruit strips. Maka perhitungan hasil analisis nilai tambah produk mango fruit strips tersaji secara rinci pada Tabel 2 dengan menggunakan dasar perhitungan $\mathrm{Kg}$ bahan baku produk dalam satu kali proses produksi.

Dalam satu kali proses produksi, produk mango fruit strips ini membutuhkan bahan baku mangga 
gedong gincu sebanyak 50kg. Dimana bahan baku tersebut sebelumnya diolah terlebih dahulu menjadi puree agar memiliki umur simpan lebih lama yakni kurang lebih selama 1 tahun. Hal tersebut sebagai salah satu bentuk antisipasi dalam memenuhi stok saat diluar musim panen. Karena produk mango fruit strips merupakan produk yang berasal dari buah asli $100 \%$ maka dalam proses pengolahannya tidak membutuhkan baku campuran lainnya seperti gula, pengawet maupun pewarna. Rasa dari produk yang dihasilkan merupakan rasa asli dari buah yaitu memiliki perpaduan rasa asam dan manis. Sehingga dalam proses pembuatannya biaya bahan baku yang dikeluarkan rata-rata adalah $\mathrm{Rp}$ 40.000/liter atau setara dengan $\mathrm{Rp}$ $40.000 / \mathrm{kg}$.

Tabel 2. Hasil Analisis Nilai Tambah Metode Hayami

\begin{tabular}{|c|c|c|c|}
\hline Variabel & No. & Sub Variabel & Keterangan \\
\hline \multirow{7}{*}{$\begin{array}{c}\text { Output, Input dan } \\
\text { Harga }\end{array}$} & 1. & Output (Kg) & 2,25 \\
\hline & 2. & Input Bahan Baku (Kg) & 50 \\
\hline & 3. & Tenaga kerja langsung (Jam/Hari) & 8 \\
\hline & 4. & Faktor konversi & 0,045 \\
\hline & 5. & Koefisien tenaga kerja (Jam/Kg) & 0,16 \\
\hline & 6. & Harga produk $(\mathrm{Rp} / \mathrm{Kg})$ & 1.000 .000 \\
\hline & 7. & Upah tenaga kerja (Rp/Jam) & 675 \\
\hline \multirow{9}{*}{$\begin{array}{l}\text { Penerimaan dan } \\
\text { Keuntungan }\end{array}$} & 8. & Harga input bahan baku $(\mathrm{Rp} / \mathrm{Kg})$ & 40.000 \\
\hline & 9. & Sumbangan input lain $(\mathrm{Rp} / \mathrm{Kg})$ & 0 \\
\hline & 10 . & Nilai Output $(\mathrm{Rp} / \mathrm{Kg})$ & 45.000 \\
\hline & 11. & a. Nilai tambah (Rp/Kg) & 5.000 \\
\hline & & b. Rasio nilai tambah (\%) & $11 \%$ \\
\hline & 12. & a. Pendapatan tenaga kerja ( $\mathrm{Rp} / \mathrm{Jam})$ & 108 \\
\hline & & b. Pangsa tenaga kerja $(\%)$ & $2,16 \%$ \\
\hline & 13. & a. Keuntungan $(\mathrm{Rp} / \mathrm{Kg})$ & 4.892 \\
\hline & & b. Tingkat keuntungan (\%) & $10,87 \%$ \\
\hline \multirow{4}{*}{$\begin{array}{c}\text { Balas Jasa Pemilik } \\
\text { Faktor Produksi }\end{array}$} & 14. & Marjin $(\mathrm{Rp} / \mathrm{Kg})$ & 5.000 \\
\hline & & d. Pendapatan tenaga kerja $(\%)$ & $2,16 \%$ \\
\hline & & e. Sumbangan input lain $(\%)$ & 0 \\
\hline & & f. Keuntungan perusahaan $(\%)$ & $97,84 \%$ \\
\hline
\end{tabular}

Sumber: Analisis Data Primer (2021)

Dari input bahan baku yang digunakan sebanyak 50kg buah mangga gedong gincu setelah melalui proses dehidrasi maka dapat menghasilkan 150 buah produk/kemasan. Dimana dalam satu kemasannya setara dengan 15 gram.
Sehingga output yang dihasilkan adalah sebanyak 2,25kg produk olahan mango fruit strips. Produk tersebut dijual dengan harga $\mathrm{Rp}$ 15.000/15gram atau setara dengan Rp 1.000.000/kg. 
Berdasarkan perhitungan dari perkalian antara faktor konversi output dan input dengan harga produk maka diperoleh hasil nilai output dari produk mango fruit strips adalah Rp 45.000/kg. Berdasarkan nilai tersebut maka dapat diketahui analisis nilai tambah dengan melakukan pengurangan nilai output dengan biaya pembelian bahan baku dan input lainnya yaitu sebesar Rp 5.000/kg. Dari hasil tersebut maka diketahui rasio nilai tambah produk mango fruit strips adalah sebesar $11 \%$ dimana setiap $\mathrm{Rp}$ 100 nilai produk mango fruit strips mengandung nilai tambah sebesar Rp 11 . Berdasarkan kriteria dari metode hayami sendiri apabila hasil nilai tambah $>0$ maka produk tersebut bernilai positif dan menandakan usaha pengolahan memiliki nilai tambah (Hayami, 1987). Sedangkan menurut kriteria pengujian Hubeis dalam dalam Maulidah dan Kusumawardani (2011) adalah jika presentase rasio nilai tambah berada $<15 \%$ maka masih tergolong kateogri rendah.

Pendapatan yang diterima oleh tenaga kerja dalam satu kali proses produksi buah mangga menjadi produk

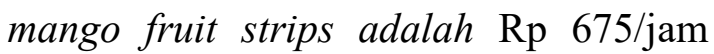
atau sebesar $2,16 \%$ dari pendapatan yang diterima oleh perusahaan. Maka dapat diketahui keuntungan yang diterima perusahaan akibat adanya nilai tambah diperoleh dari pengurangan nilai tambah dengan pendapatan tenaga kerja yaitu didapatkan hasil sebesar $\mathrm{Rp} 4.892 / \mathrm{kg}$ atau tingkat keuntungannya sebesar 10,87\%. Sehingga apabila dibandingkan antara produk mango fruit strips dengan penjualan bahan baku dalam bentuk segar memiliki nilai yang lebih tinggi dari bahan segar sebesar Rp 5.000/kg. Besarnya margin yang diperoleh tersebut $2,16 \%$ menyumbang pendapatan tenaga kerja dan $97,84 \%$ sisanya menjadi keuntungan perusahaan karena tidak ada sumbangan bahan input lainnya yang digunakan. Hasil presentase keuntungan dari margin akibat proses pengolahan yang memiliki nilai lebih dari 50\% mengindikasikan bahwa penjualan produk buah mangga dalam bentuk produk olahan seperti mango fruit strips lebih menguntungkan dari pada menjual hanya dalam bentuk buah segar.

Dapat terlihat bahwa nilai tambah dari produk mango fruit strips memiliki nilai yang lebih kecil diantara produk olahan lainnya seperti minuman sari buah, dodol dan keripik. Namun dibandingkan dengan nilai tambah produk olahan menjadi puree, mango fruit strips masih memiliki nilai yang lebih besar. Meskipun demikian, 
perhitungan nilai tambah ini pasti akan berbeda-beda sesuai dengan output yang diinginkan oleh produsen atau perusahaan. Untuk mango fruit strips sendiri karena perusahaan mengedepankan dalam segi manfaat produknya maka penggunaan bahan bakunya pun hanya berasal dari buah mangga itu sendiri tanpa ada sumbangan bahan baku lainnya sehingga setiap 1 kemasan produk yang dihasilkan dapat dijamin memiliki manfaat yang setara dengan mengonsumsi 1 buah mangga.

\section{KESIMPULAN DAN SARAN}

Usaha pengolahan buah mangga menjadi produk inovasi camilan sehat yaitu mango fruit strips memiliki nilai positif untuk dipasarkan. Hal ini dikarenakan besarnya nilai tambah dari produk mango fruit strips adalah $\mathrm{Rp}$ $5.000 / \mathrm{kg}$ dengan setiap $\mathrm{Rp} 100$ nilai produk mango fruit strips memperoleh nilai tambah sebesar Rp 11. Berdasarkan kriteria dari metode hayami bahwa jika hasil nilai tambah menunjukkan $>0$ maka produk bernilai positif dan menandakan kegiatan pengolahan memiliki nilai tambah. Namun dengan hasil presentase rasio yang $<15 \%$ menandakan nilai tambah masih dalam kategori rendah. Perolehan margin sebesar Rp 5.000/kg dengan $97,84 \%$ dari hasil tersebut menjadi keuntungan perusahaan maka mengindikasikan bahwa penjualan produk buah mangga dalam bentuk produk olahan seperti mango fruit strips lebih menguntungkan dari pada menjual produk hanya dalam bentuk segar.

\section{UCAPAN TERIMA KASIH}

Penelitian ini tidak dapat berjalan apabila tidak adanya informasi dari informan. Maka dari itu penulis mengucapkan terimakasih sebanyakbanyaknya kepada Muhammad Nur Rijaldi selaku CEO dan Hibban Farhan Haibah selaku CMO dari Frutivez yang sudah memberikan waktu dan kesempatannya untuk dapat berbagi ilmu dan informasi kepada penulis.

\section{DAFTAR PUSTAKA}

[BPS]. Badan Pusat Statistik. (2019). Statistik Tanaman Buah-buahan dan Tanaman Sayur-sayuran Indonesia.

Anitasari, S., Sunartomo, A. F., \& Ridjal, J. A. (2014). Manajemen Rantai Pasokan Produk Olahan Mangga Arum Manis.

De la Fuente, V. (2016). Mango Processing and Opportunities. Philippine Mango Industry, Inc.

Griffin, A. (1997). PDMA research on new product development practices: Updating trends and benchmarking best practices. Journal of Product Innovation Management: An International 
Publication of The Product Development \& Management Association, 14(6), 429-458.

Hayami, Y. (1987). Agricultural marketing and processing in upland Java. CGPRT Centre.

Herdiyandi, H., Rusman, Y., \& Yusuf, M. N. (2017). Analisis Nilai Tambah Agroindustri Tepung Tapioka Di Desa Negaratengah Kecamatan Cineam Kabupaten Tasikmalaya (Studi Kasus Pada Seorang PengusahaAgroindustri Tepung Tapioka di Desa Negaratengah Kecamatan Cineam Kabupaten Tasikmalaya). Jurnal Ilmiah Mahasiswa AGROINFO GALUH, 2(2), 81-86.

Maulidah, S., \& Kusumawardani, F. (2011). Nilai tambah agroindustri belimbing manis (Averrhoa carambola L.) dan optimalisasi output sebagai upaya peningkatan pendapatan. Agricultural SocioEconomics Journal, 11(1), 19.

Rasmikayati, E., Kusumo, R. A. B., Mukti, G. W., Saefudin, B. R. (2020). Comparison of Willingness to Process Fresh Mango into Processed Mango Products between Mango Farmers In Majalengka and Kuningan Regency, West Java. International Journal of Scientific and Research Publications (IJSRP) 10(12) (ISSN: 2250-3153), DOI: https://dx.doi.org/10.29322/IJSRP. 10.12.2020.p10847.

Rasmikayati, E., Saefudin, B. R., Nadapdap, H. J., \& Awaliyah, F. (2020). Agribusiness Behavior Of Mango Farmers In The District Of Panyingkiran Majalengka Regencybased On Mango Ownership. Sosiohumaniora, 22(2), 206-213.
Rasmikayati, E., Sulistyowati, L., \& Saefudin, B. R. (2017). Risiko Produksi dan Pemasaran Terhadap Pendapatan Petani Mangga: Kelompok Mana yang Paling Berisiko. Mimbar Agribisnis: Jurnal Pemikiran Masyarakat Ilmiah Berwawasan Agribisnis, 3(2), 105-116.

Royanti, D. (2018). Analisis Keuntungan dan Nilai Tambah Pada Agroindustri Puree Mangga (Studi Kasus di CV Promindo Utama, Desa Losari Lor, Kecamatan Losari, Kabupaten Cirebon, Jawa Barat) (Doctoral dissertation).

Siafunda, M. (2019). Study of Marketing and Processing of Mango Enterprise with a View to Reduce Wastage Among Local Mango Producers in Zambia. Texila International Journal of Management Special Edition. DOI: https://dx.doi.org/10.21522/TIJMG. 2015.SE.19.01.Art022.

Suardani, N. M. A., Darmadi, N. M., \& Semarayani, A. M. (2016). Teknologi Pengolahan dan Pengawetan Jahe sebagai Upaya Peningkatan Kesejahteraan Kelompok Wanita Tani di Desa Petang. Prosiding Semnas Hasil Pengabdian Masyarakat.

Zainudhin, Z. (2016, December 14). Nilai Tambah Pengolahan Mangga Gedong Gincu di Kabupaten Majalengka. Retrieved February 02, 2021, from https://www.agrotani.com/nilaitambah-pengolahan-manggagedong-gincu-kabupatenmajalengka/ 